\title{
Commentary
}

\section{Counting gender and sexual identity in the Australian census}

\author{
Anthony Lyons* La Trobe University \\ Mary Lou Rasmussen Australian National University \\ Joel Anderson La Trobe University and Australian Catholic University \\ Edith Gray Australian National University \\ * Corresponding author. Email: a.lyons@latrobe.edu.au. Address: Australian Research Centre in Sex, \\ Health and Society, School of Psychology and Public Health, Building NR6, La Trobe University, \\ Bundoora, Victoria, 3086, Australia.
}

Paper received 12 February 2021; accepted 27 April 2021; published 31 May 2021

\section{Introduction}

The Australian Census of Population and Housing (hereafter referred to as the 'census'), serves as an important barometer of the nation. In this article, we outline why it is so important to include comprehensive gender and sexual identity questions in the census as well as several considerations that ought to be addressed in the course of including such questions. The census provides a count for electoral representation, informs government and non-government policies and services, and ultimately reveals who we are as a nation, how the population changes over time, and how the diversity of Australia's relatively small population is spread across a vast landmass. It also serves as an important resource for numerous other surveys by providing a complete count of the population to inform sampling and weighting of data and thus enabling population representative data gathering. For these and other reasons, it is crucial that the census captures as much of the diversity in Australia's population as possible. Without this knowledge, important subpopulations are rendered invisible and initiatives to collect representative data of these populations in other surveys are severely limited, if not impossible. Australia's gender and sexually diverse population is one such population that is not fully counted.

\section{Including gender and sexual identity in the census}

\subsection{What we mean by gender and sexual identity questions}

Surveys conducted in Australia reveal a large diversity in gender and sexual identity (Hill et al. 2020; Leonard et al. 2012). Although representative data are lacking, estimates of the size of Australia's gender and sexually diverse population broadly range from $3.5 \%$ to $11 \%$, or 900,000 to 2.8 million (Department of Health 2012; Wilson et al. 2020; Zhang et al. 2020). This includes people who identify with one or more diverse sexual identities, such as lesbian, gay, bisexual, pansexual, or queer. It also includes people who are trans and gender diverse, including non-binary genders. Despite this, population surveys, including the census, rarely involve comprehensive questions on gender and 
sexual identity that would enable identification of the many different gender and sexual identity populations living in Australia (Lyons et al. 2020).

In simple terms, we refer to gender and sexual identity questions as demographic variables. In other words, these are questions where people have the opportunity to report their gender, such as woman, man, trans woman, trans man, or non-binary, and separately from this, their sexual identity, such as lesbian, gay, bisexual, pansexual, or queer. Gender and sexual identities comprise significant elements of a person's background that define and shape many aspects of their lives, such as raising families, employment, and engagement with services (Hill et al. 2020). These identities are important aspects of Australia's diversity that need to be captured in population surveys.

By gender, we refer to how people identify or describe themselves. This is an important distinction, as the terms 'sex' and 'gender' are typically conceptualised in different ways despite often being treated as though they were synonymous (e.g., Connell 2002; Hammarström and Annandale 2012). As an example, the Australian Bureau of Statistics (ABS) recently published a Standard for Sex, Gender, Variations of Sex Characteristics and Sexual Orientation Variables (ABS 2021). This standard is aligned with guidelines from the Australian Government Attorney-General's Department (Australian Government 2013) and outlines sex and gender in distinct ways. The standard utilises the term 'sex' to refer to biological characteristics. This is most commonly assigned to an individual at birth, usually male or female, or may be recorded differently in some instances when a variation in their sex characteristics is evident. In contrast, the term 'gender' is used to refer to how a person describes themselves, which may not necessarily align with the sex assigned to them at birth. For instance, a person who is trans may have been assigned female at birth but describe themselves as, and importantly are, a man. As shown by the recent Private Lives 3 national survey, many people in Australia also describe themselves in different ways, such as neither exclusively male nor female (e.g., non-binary; Hill et al. 2020).

The term, 'sexual identity', typically refers to how a person experiences or expresses themselves sexually or romantically (Durso and Gates 2013), which includes diverse identity labels such as lesbian, gay, bisexual, pansexual, heterosexual, and queer. The term 'sexual orientation' is usually used as a broader application to refer to different components of sexuality, which can include sexual identity, sexual behaviour, and sexual attraction (Katz-Wise 2015). For example, people who engage in sex with someone of the same sex might describe themselves in different ways, such as lesbian, gay or bisexual. While different components of sexual orientation are important to consider, sexual identity is the more common focus. Though depending on the particular focus of a survey (e.g., a survey of sexual behaviour), researchers might need to know about identity, behaviour, and attraction.

It is worth noting that this account of conceptual distinctions is somewhat simplified for the purposes of this article. Extensive theoretical and conceptual work have been conducted over many years and decades. For example, arguments have been made to suggest that gender and sexual identity are not always inseparable (Butler 2006). However, for the purposes of this article, a main point to note is that 'sex', 'gender', and 'sexual identity' are terms that have particular shared meanings and distinctions, which need to inform the framing of gender and sexual identity questions. 


\subsection{Why it is essential these data are collected in Australia}

Australia's diverse gender and sexual identity population continues to experience stigma-related harm (Hill et al. 2020) and faces numerous significant social and health-related burdens such as physical and mental health challenges (Perales 2019), suicidality (Raifman et al. 2020), family-related challenges (Perales et al. 2019), discrimination and victimisation (Hill et al. 2020), homelessness (Hill et al. 2020; Hill et al. 2021), poverty (Hill et al. 2020), and barriers to accessing services (Alba et al. 2020). Critical differences are also apparent between subpopulations in the extent to which particular burdens are experienced, such as differences between those who are cisgender and trans or bisexual and pansexual (Hill et al. 2020). Gathering comprehensive population-level data is therefore crucial. It is only with such data that policies and services can be designed and targeted effectively to areas of need. Data collection also needs to be repeated regularly to enable monitoring of the progress of initiatives and to thus allow necessary adjustments to be made in policy settings and service delivery.

Significant social change has occurred over recent decades, with associated shifts in understandings and expressions of gender and sexuality. As mentioned earlier, gender and sexuality are integral aspects of people's lives and it is not possible to have a truly informative picture of the nation without having data that reflects this diversity. Recognising the significant implications to social, health, and economic outcomes, Australia's gender and sexually diverse population is identified as a key priority group in government strategies around the country. Examples include the Federal Government's Aged Care Diversity Framework, the forthcoming Victorian LGBTIQ+ Strategy, Western Australia's WA LGBTI Health Strategy and the Australian Capital Territory's Capital of Equality Strategy. However, effectively operationalising and monitoring the progress of these and other strategies and policies depend on the continued availability of comprehensive data of gender and sexual identity. In addition to ensuring the knowledge required to address significant national challenges, gathering comprehensive data on gender and sexual identity via population research is fundamental to understanding the demography of the nation.

\subsection{Why these data should be collected in the Australian census}

The Australian census is vital to providing essential information about Australia's population. The data collected in the census is used by a wide range of individuals and organisations in public, private and not-for-profit sectors to make informed planning and policy decisions for all Australians. A major strength of the census is its coverage: it includes the whole population of Australia, thereby providing the data required to cover small geographic areas and population groups that may be otherwise missed, or misrepresented, in smaller surveys. While a broad range of information is collected about people that is useful for identifying communities, information that would enable a comprehensive count of gender and sexually diverse populations is currently not collected. In 2018, it was announced that eight new topics would be tested for inclusion in the 2021 Census. These eight topics included 'non-binary sex and/or gender identity' and 'sexual orientation' (ABS 2018). These topics were developed following extensive public consultation but were later dropped from testing.

Despite this, the public consultation process identified the value of collecting comprehensive information on gender and sexual identity in the census. The process found that gender and sexually diverse communities often have higher levels of vulnerability including experiences of discrimination, 
abuse and mental health issues that require targeted support, and that information collected via the census would help to inform the development of policy, allocation of resources and delivery of services to people from these communities (ABS 2020). Despite the decision not to proceed with questions in the next census, as mentioned earlier the ABS has since released a new Standard for Sex, Gender, Variations of Sex Characteristics and Sexual Orientation Variables (ABS 2021), which was developed through research, consultation, and testing, and could potentially serve as a foundation or starting point for the future inclusion of questions in the census. While specific questions for the census would need to be identified, not having these data collected in the census renders these communities invisible in national statistics. Service providers are left in the unenviable position of having to make educated guesses about where to best put their resources. While some information can be gleaned from survey data, there are no benchmarks which can be used to create sample weights for these surveys. As mentioned earlier, census data are required for population estimates that reflect Australia's gender and sexual identities. This would enable population representative surveys to be conducted in areas not directly examined by the census, such as surveys of health, in addition to providing valuable knowledge on topics directly examined in the census, such as housing, income, employment, and family circumstances.

\subsection{Potential issues to consider in asking comprehensive questions of sex, gender, and sexual identity}

There are at least several considerations that need to be taken into account in identifying census questions on gender and sexual identity. A small but important literature has empirically analysed the consequences for not asking questions about sex, gender and sexual identity correctly. The literature on this topic has debated both strengths and limitations in the specific framing of questions, including the associated response options (Lyons et al. 2020; Sullivan 2020; Waite and Denier 2019). How these questions are framed might appear inconsequential, but subtle differences can result in different interpretations, and thus potentially different responses, by respondents. For instance, prescriptive terminology in questions on sexual identity (e.g., 'Are you...' rather than 'how do you identify...') might result in respondents feeling obliged to select from identities that are more commonly used and understood, rather than allowing themselves to self-identify more freely.

Relatedly, it is important to highlight that how questions are asked by survey designers can frame the social categories that are valued and recognised in society. More specifically, it is argued that how questions are framed produces a 'social reality' (Law et al. 2011), where a population is defined or generated by the question and its response options. Accordingly, it is the responsibility of survey designers to think carefully about how they craft gender and sexual identity questions, the response options they choose to provide, and how they explain to survey respondents what is being asked of them. For example, asking a question where respondents indicate their sex might conceivably be answered in differing ways, such as the sex assigned to them at birth, their current sex (which may be different to that assigned to them at birth, such as those with a trans history), or their gender. In the absence of clear framing and explanation, respondents may be left to subjectively interpret these questions. Reflecting current best practice, the ABS has recommended in its latest Standard for Sex, Gender, Variations of Sex Characteristics and Sexual Orientation to apply specific question wording, such as "What was your sex recorded at birth?" and potentially asking respondents to indicate their gender in a separate question (ABS, 2021). 
As noted elsewhere (e.g., Lyons et al. 2020), there is debate about the advantages and disadvantages of allowing participants to respond with open ended questions, about the use of 'other' categories, and about single- versus multi-select answers. It is important to recognise that, contrary to oftenheld beliefs, gender and sexual identity are neither simple nor synonymous constructs, and that often individuals need to be able to select combinations of identities (for further discussion, see Lyons et al. 2020; Ruberg and Ruelos 2020). Although this may present some challenges when designing questions, if a question cannot be answered in a way that reflects a person's background, then the respondent is left with the choice of either not answering the question (and thus not being counted) or answering in a way that does not reflect them (thus undermining the integrity of the data). Therefore, it is not only important to include gender and sexual identity questions that better reflect Australia's diverse population, but also give thought to how these questions are designed and the conclusions that might feasibly be drawn from the resulting data. Engaging in consultation with different communities and stakeholders as well as researching and testing approaches are therefore important initiatives to undertake prior to settling on an optimal design of questions that captures diversity as well as being understood by respondents. This could also include developing and testing approaches to ensure that respondents feel comfortable in answering the questions and thus minimising non-responses. It will also be important to review approaches over time to ensure that questions included in the census remain relevant to any future changes in sexual identity and gender categories.

\subsection{Are other countries doing work to gather similar information?}

Statistics New Zealand, in writing about their decision to incorporate more questions on sex, gender identity and sexual orientation in their next census, note that data that captures the diversity of this population in terms of sex, gender identity, and sexual orientation has been very limited around the world. In New Zealand, the government has argued for the "'gender by default' principle ... an approach that defaults to the collection of gender data as opposed to sex at birth.... Collection of sex at birth information should be viewed as an exception where there is a specific need" (Statistics New Zealand 2020). The New Zealand government is making this change because in "most cases a person's gender - their social and personal identity - is most relevant for policy making and research rather than their sex at birth" (Statistics New Zealand 2020). The New Zealand government has also specified that questions, similar to those relating to ethnicity, are suitable for all people, regardless of their age.

These issues are being treated quite differently in the United Kingdom. In December 2018, the Office for National Statistics (ONS), which is responsible for the census in England and Wales, set out its recommendations for the next census in the White Paper 'Help Shape our Future: The 2021 Census of Population and Housing in England and Wales' (ONS 2018). This White Paper gives the recommendation that the census includes, for the first time, a voluntary gender identity question, in addition to retaining a binary female/male sex question. The ONS also recommended introducing a new question enquiring about an individual's sexual orientation, where they are aged 16 years and over. In this proposal, the sex question would remain unchanged and only people aged 16 years and over would have the opportunity to voluntarily complete a question related to their gender identity and sexual orientation. In 2022, the Scottish government will also ask everyone aged 16 years and over to voluntarily disclose their sexual orientation. Respondents will be presented the opportunity 
to identify themselves as 'Straight/Heterosexual', 'Gay or Lesbian', 'Bisexual' or 'Other sexual orientation, please write in...'.

In discussing parliamentary debates about the design of the Scottish census, Kevin Guyan argues that the decision to include a non-binary sex question "highlighted the existence of two schools of thought: one understood the census as an exercise in accurate, data collection; the other, understood the census as a method to construct and/or protect governable identity categories" (Guyan 2021 p. 6). The contested politics relating to how a census constructs governable categories is apparent when one looks at how decisions are made about how old a person can be before they can declare their gender identity. The age at which a person can legally obtain gender recognition internationally varies from, for example, no age limit in the Australian Capital Territory, British Columbia, and Argentina, to 18 years in New Zealand. Governments are clearly constructing governable identity categories when they are explicitly excluding young people from filling out the questions related to gender identity and sexual orientation. Guyan further notes that "any minor errors in the [census] count will likely have a disproportionately large effect on findings" (Guyan 2021 , p. 8) because LGBTQ populations are already a comparatively small percentage of the whole population. Consequently, the decision to determine participation by age may be one of the 'minor errors' that has explicit effects in determining the way in which these populations are counted in Scotland and elsewhere.

\subsection{How Australia might learn from others to address potential issues in collecting data related to sex, gender, and sexual identity}

Statistics New Zealand are endeavouring to be as capacious as possible in counting sex, gender and sexuality diversity within their population. This is evidenced by their inviting respondents of any age to answer sex and gender questions, incorporating Maori translations to describe gender and sex classifications, as well as moving away from terms like gender diverse toward the term "another gender". They are also restricting use of the sex at birth question, following in the footsteps of Statistics Canada, arguing that this type of specific information is only required in the limited circumstances where there is a need to disaggregate cisgender and trans populations.

Statistics New Zealand are also flagging that the current consultations on the census will need to be ongoing because the ways in which people understand sex, gender and sexual identity are constantly changing, citing the example of the term non-binary, which was little used at the time of the last census, but is now regularly deployed by community members (Veale et al. 2019). For Australian purposes, there needs to be similar recognition that issues related to counting sexual and gender identity will likely not be resolved in one attempt, but will require ongoing attention, in line with changes in community norms in this space.

\section{Concluding comments}

As other jurisdictions prepare to improve how they count gender and sexual identity in their censuses, such as New Zealand and Scotland, a strong case exists for Australia to do similarly and an opportunity exists to learn from the experiences of these countries. While continued work may be required to identify and adapt questions over time, it is an endeavour that has many important benefits. A more comprehensive account of the diversity of gender and sexual identity in Australia 
would not only provide the foundation for population representative research involving gender and sexually diverse populations, it would enable a more thorough and contemporary assessment of the nation's demography. These are both critical to advancing the knowledge required to address significant challenges faced by Australia's gender and sexually diverse population and thereby improve overall national social, health and economic outcomes.

We have argued that it is important to take a range of considerations into account in formulating gender and sexual identity questions, such as the choice of response options and the wording of questions, as well as remaining cognisant that how these are framed will shape the data, including how specific sub-populations are understood. The recently released ABS Standard for Sex, Gender, Variations of Sex Characteristics and Sexual Orientation Variables may serve as a helpful basis for further investigation and community consultation. This will be integral to identifying questions that satisfy the overall requirements of the census while providing an important and long overdue count of Australia's diversity in relation to sex, gender and sexual identity. It is also important to consider whether questions related to sex, gender and sexual identity will require amendment at each census in order to keep pace with the rapid shifts occurring in Australia in this domain.

\section{References}

ABS (2018) ABS tests topics for 2021 Census to reflect changing nation. Media Release. Canberra: Australian Bureau of Statistics. https://www.abs.gov.au/ausstats/abs@.nsf/Lookup/by\%20Subject/2007.0.55.001 2021 Media \%20Release ${ }^{\sim}$ ABS\%20tests\%20topics\%20for\%202021\%20Census\%20\%20(Media\%20Release) 100 00. Accessed on 3 February 2021.

ABS (2020) 2021 Census topics and data release plan. Canberra: Australian Bureau of Statistics. https://www.abs.gov.au/statistics/research/2021-census-topics-and-data-release-plan\#topicsnot-included-in-the-2021-census. Accessed on 3 February 2021.

ABS (2021) Standard for sex, gender, variations of sex characteristics and sexual orientation variables. Canberra: Australian Bureau of Statistics. https://www.abs.gov.au/statistics/standards/standardsex-gender-variations-sex-characteristics-and-sexual-orientation-variables/latest-release. Accessed on 2 February 2021.

Alba B, Lyons A, Waling A, Minichiello V, Hughes M, Barrett C, Fredriksen-Goldsen K and Edmonds S (2020) Older lesbian and gay adults' perceptions of barriers and facilitators to accessing health and aged care services in Australia. Health and Social Care in the Community. https://doi.org/10.1111/hsc.13125

Australian Government (2013) Australian Government guidelines for the recognition of sex and gender. Canberra: Australian Government Attorney General's Department. https://www.ag.gov.au/sites/default/files/202003/AustralianGovernmentGuidelinesontheRecognitionofSexandGender.pdf. Accessed on 1 February 2021.

Butler J (2006) Gender Trouble. New York: Routledge.

Byron P, Robards B, Hanckel B, Vivienne S and Churchill B (2019) "Hey, I'm Having These Experiences": Tumblr use and young people's queer (dis) connections. International Journal of Communication 13: 2239-2259. https://ijoc.org/index.php/ijoc/article/view/9677

Connell R W (2002) Gender. Cambridge: Polity.

Department of Health (2012) National LGBTI Ageing and Aged Care Strategy. Canberra: Australian Government. 
Durso L E and Gates G J (2013) Best practices: collecting and analysing data on sexual minorities. In A Baumle (Ed), International Handbook on the Demography of Sexuality. Dordrecht: Springer.

Guyan K (2021) Constructing a queer population? Asking about sexual orientation in Scotland's 2022 census. Journal of Gender Studies. https://doi.org/10.1080/09589236.2020.1866513

Hammarström A and Annandale E (2012) A conceptual muddle: an empirical analysis of the use of 'sex' and 'gender' in 'gender-specific medicine' journals. Plos One 7: e34193. https://doi.org/10.1371/journal.pone.0034193

Hill A O, Bourne A, McNair R, Carman M and Lyons A (2020) Private Lives 3: The health and wellbeing of LGBTIQ people in Australia. Melbourne: La Trobe University. https://www.latrobe.edu.au/arcshs/publications/private-lives/private-lives-3

Hill A O, Lyons A, Jones J, McGowan I, Carman M, Parsons M, Power J and Bourne A (2021) Writing Themselves In 4: The health and wellbeing of LGBTQA+ young people in Australia. Melbourne: La Trobe University. https://www.latrobe.edu.au/arcshs/publications/writing-themselves-inpublications/writing-themselves-in-4

Katz-Wise S L (2015) Sexual fluidity in young adult women and men: associations with sexual orientation and sexual identity. Psychology and Sexuality 6(2): 189-208. https://doi.org/10.1080/19419899.2013.876445

Law J, Ruppert E and Savage M (2011) The double social life of methods (CRESC Working Paper Series, No. 95). Milton Keynes: Open University.

Leonard W, Pitts M, Mitchell A, Lyons A, Smith A, Patel S, Couch M and Barrett A (2012) Private Lives 2: The second national survey of the health and wellbeing of gay, lesbian, bisexual and transgender (GLBT) Australians. Melbourne: La Trobe University. https://www.latrobe.edu.au/arcshs/publications/private-lives

Lyons A, Anderson J R, Rasmussen M L and Gray E (2020) Toward making sexual and gender diverse populations count in Australia. Australian Population Studies 4(2): 14-29. https://doi.org/10.37970/aps.v4i2.69

ONS (2018). Help shape our future: The 2021 Census of Population and Housing in England and Wales. London, England: Office of National Statistics. https://assets.publishing.service.gov.uk/government/uploads/system/uploads/attachment data/ file/765089/Census2021WhitePaper.pdf. Accessed on 2 February 2021.

Perales F (2019) The health and wellbeing of Australian lesbian, gay and bisexual people: a systematic assessment using a longitudinal national sample. Australian and New Zealand Journal of Public Health 4: 281-287. https://doi.org/10.1111/1753-6405.12855

Perales F, Simpson Reeves L, Plage S and Baxter J (2019) The family lives of Australian lesbian, gay and bisexual people: A review of the literature and a research agenda. Sexuality Research and Social Policy 17: 43-60. https://doi.org/10.1007/s13178-018-0367-4

Raifman J, Charlton B M, Arrington-Sanders R, Chan P A, Rusley J, Mayer K H, Stein M D, Austin B and McConnell M (2020) Sexual orientation and suicide attempt disparities among US adolescents: 2009-2017. Pediatrics 145: e20191658. https://doi.org/10.1542/peds.2019-1658

Ruberg B and Ruelos S (2020) Data for queer lives: How LGBTQ gender and sexuality identities challenge norms of demographics. Big Data and Society 7: 2053951720933286. https://doi.org/10.1177/2053951720933286

Stats NZ (2020) Sex and gender identity statistical standards: Consultation. Wellington, New Zealand: Stats NZ. https://www.stats.govt.nz/consultations/sex-and-gender-identity-statistical-standardsconsultation. Accessed on 2 February 2021.

Sullivan A (2020) Sex and the census: why surveys should not conflate sex and gender identity. International Journal of Social Research Methodology 23(5): 517-524. https://doi.org/10.1080/13645579.2020.1768346 
Veale J, Byrne J, Tan K, Guy S, Yee A, Nopera T and Bentham, R. (2019). Counting Ourselves: The Health and Wellbeing of Trans and Non-binary People in Aotearoa New Zealand. Hamilton, New Zealand: Transgender Health Research Lab, University of Waikato. https://www.countingourselves.nz/wpcontent/uploads/2020/01/Counting-Ourselves Report-Dec-19-Online.pdf. Accessed 2 February 2021.

Waite S and Denier N (2019) A research note on Canada's LGBT data landscape: where we are and what the future holds. Canadian Review of Sociology 56(1): 93-117. https://doi.org/10.1111/cars.12232

Wilson T, Temple J, Lyons A and Shalley F (2020) What is the size of Australia's sexual minority population? BMC Research Notes 13: 535. https://doi.org/10.1186/s13104-020-05383-w

Zhang Q, Goodman M, Adams N, Corneil T, Hashemi L, Kreukels B, Motmans J, Snyder R and Coleman E (2020) Epidemiological considerations in transgender health: A systematic review with focus on higher quality data. International Journal of Transgender Health 21(2): 125-137. https://doi.org/10.1080/26895269.2020.1753136 